\title{
Entre el lugar y la línea: la constitución de las fronteras coloniales patagónicas 1780-1792
}

\author{
Perla Zusman \\ Universidad Autónoma de Barcelona
}

\begin{abstract}
Resumen
En este artículo se hace una análisis de algunas de las acciones adelantadas por la Corona española con el fin de avanzar en la ocupación de la Patagonia, a mediados del siglo XVIII y defender la zona de una posible penetración inglesa. La autora enmarca su trabajo dentro de las ideas que se han planteado en los estudios sobre las fronteras medievales de la península Ibérica, argumentando que constituyen un modelo más adecuado que el de Frederick Turner, utilizado tradicionalmente. Desde allí, elabora su propia interpretación a partir de elementos como: la producción cartográfica, los establecimientos patagónicos, la población indígena en la zona, las repercusiones que sobre ella trae la expansión colonial y los diversos intereses que guiaron las distintas políticas colonizadoras y determinaron el avance de las fronteras coloniales en el extremo sur del continente americano.
\end{abstract}

\begin{abstract}
En este artículo se hace una análisis de algunas de las acciones adelantadas por la Corona española con el fin de avanzar en la ocupación de la Patagonia, a mediados del siglo XVIII y defender la zona de una posible penetración inglesa. La autora enmarca su trabajo dentro de las ideas que se han planteado en los estudios sobre las fronteras medievales de la península Ibérica, argumentando que constituyen un modelo más adecuado que el de Frederick Turner, utilizado tradicionalmente. Desde allí, elabora su propia interpretación a partir de elementos como: la producción cartográfica, los establecimientos patagónicos, la población indígena en la zona, las repercusiones que sobre ella trae la expansión colonial y los diversos intereses que guiaron las distintas políticas colonizadoras y determinaron el avance de las fronteras coloniales en el extremo sur del continente americano.
\end{abstract}




\section{Fronteras de hoy, fronteras de ayer}

La preocupación y las nuevas formas de abordaje de la cuestión de las fronteras en diversos campos académicos guarda relación con la relevancia que hoy la problemática presenta frente a un mundo que se está reconfigurando a más de diez años de la caída del bloque soviético, al aumento de las reivindicaciones de autonomía nacionales étnicoreligiosas y a la formación de bloques supranacionales o intergubernamentales. ${ }^{1}$

Puede considerarse que la temática de las fronteras ha contribuido a la constitución de la tradición disciplinar. ${ }^{2}$ De forma sucinta, podemos afirmar que los estudios en este campo han sido desarrollados siguiendo dos líneas de abordaje, uno vinculado a la definición de los límites internacionales y el otro ligado al avance de la ocupación sobre territorios no incorporados a la economía mundial. Mientras que la primera perspectiva tiene su raigambre estrictamente en los trabajos clásicos de la geografía política y de la geopolítica, (Frederich Ratzel, Karl Haushofer, Otto Schluter, Jacques Ancel, Camille Vallaux, Jean Brunhes), ${ }^{3}$ la segunda visión, inspirada en la perspectiva turneriana, puede ser rastreada en los estudios de geografía política, de geopolítica y de geografía agraria (Bowman, Lattimore, Mikesell, Monbeig, Parsons). ${ }^{4}$

En general estos estudios o han sido de carácter empírico ${ }^{5}$ o se han ocupado de definir tipologías y funciones de fronteras. ${ }^{6}$ Algunos trabajos disciplinares recientes rompen con las visiones naturalizadas para conceptualizarlas como construcciones políticas, sociales

\footnotetext{
${ }^{1}$ W. R. Douglas, “¿Las fronteras: muros o puentes?” Historia y fuente oral, no. 12 (1994); H. Driessen, "La puerta trasera de Europa: Notas etnográficas sobre la frontera húmeda entre España y Marruecos," Historia y fuente oral, no. 12 (1994); W. Kavanagh, "La naturaleza de las fronteras," Historia y fuente oral, no. 12 (1994); y G. H. Hanson, "Economic Integration, Intraindustry Trade and Frontier Regions," European Economic Review 40, nos. 3-5 (abril 1996): 941.

${ }^{2}$ David N. Livingstone, The Geographical Tradition: Episodes in the History of a Contested Enterprise (Oxford: Blackwell, 1992).

${ }^{3}$ J. Nogué y J. Vicente, Los territorios de la globalización: Geopolítica de un mundo en transformación (Barcelona: Ariel, 2001).

${ }^{4}$ A. Henessy, The Frontier in Latin American History (Londres: Edward Arnold, 1978); C. Reboratti, "Fronteras agrarias en América Latina," Geocrítica, no. 87 (1990); http:/www.ub.es/geocrit/geo87.htm.

${ }^{5}$ M. Foucher, L'invention des frontières (París: Fondation pour les Études de Défense Nationale, 1986); Idem, Fronts et frontiers: Un tour du monde geopolitique (París: Fayard, 1991).

${ }^{6}$ J. V. R. Prescott, Political Frontiers and Boundaries (Londres: Allen \& Unwin, 1990).
} 
o discursivas ${ }^{7}$ con profundos significados simbólicos, culturales y religiosos para las comunidades sociales. ${ }^{8}$

El resurgimiento de la cuestión fronteriza tanto dentro como fuera de la geografía, también ha motivado la revisión de las formas en que ella ha sido interpretada en otros períodos históricos ${ }^{9}$ particularmente en el ámbito latinoamericano. ${ }^{10}$ En estos contextos, las visiones de la frontera como ámbito de diferenciación son yuxtapuestas con aquellas que la presentan como lugar de la negociación, la alianza, de intercambio, ${ }^{11}$ como

\footnotetext{
${ }^{7}$ K. J. Dodds, "Geopolitics and Foreign Policy: Recent Developments in Anglo-American Political Geography and International Relations," Progress in Human Geography 18 (1994); D. Sibley, Geographies of Exclusion: Society and Difference in the West (Londres: Routledge, 1995); y S. Hasson, "Frontier and Periphery as Symbolic Landscapes," Ecumene 3 (1996): 146-66.

${ }^{8}$ D. Newman y A. Paasi, "Fences and Neighbours in the Posmodern World: Boundary Narratives in Political Geography," Progress in Human Geography 22, no. 2 (1998): 186-207; T. Wilson y H. Donnan, Border Identities (Cambridge: Cambridge University Press, 1998); y A. Grimson, Fronteras, naciones e identidades: La periferia como centro (Buenos Aires: CICCUS, 2000).

${ }^{9}$ D. Weber, La frontera española en América del Norte (México, D.F.: Fondo de Cultura Económica, 2000); P. Sahlins, Fronteres $i$ identitats: la formació d'Espanya i França a la Cerdanya, s. XVII-XIX (Vic: Eumo, 1993); Peter Sahlins, "Natural Frontiers Revisited: France's Boundaries since the Seventeenth Century," American Historical Review 95, no. 5 (diciembre 1990); y J. Adelman y Stephen Aron, "From Borderlands to Borders: Empire, Nation-States and the Peoples in between in North American History," American Historical Review 104, no. 3 (junio 1999).

${ }^{10}$ L. Osorio Machado, "Artificio político en el origen de la unidad territorial de Brasil," en Los espacios acotados: Geografia y dominación social, ed. H. Capel (Barcelona: Publicacions Universitat de Barcelona, 1990); S. Villalobos, "Tres siglos y medio de vida fronteriza chilena," en Estudios (nuevos y viejos) sobre la frontera, coord. F. de Solano y S. Bernabeu, Anexos de Revista de Indias, no. 4 (Madrid: Consejo Superior de Investigaciones Científicas, 1991), 289-359; L. Osorio Machado, "Misiones y Estado Colonial: Confrontación entre dos formas de control territorial en la Amazonia del setecientos," en Ciencia, vida y espacio en Iberoamérica, coord. José L. Peset, vol. 3 (Madrid: Consejo Superior de Investigaciones Científicas, 1989); Alberto J. Gullon Abao, La frontera del chaco en la Gobernación del Tucumán, 1750-1810 (Cádiz: Universidad de Cádiz, Servicio de Publicaciones, 1993); David J. Weber y Jane M. Rausch, eds., Where Cultures Meet: Frontiers in Latin American History (Wilmington: S.R. Books, 1994); M. Gascón, "La articulación de Buenos Aires a la frontera sur del Imperio Español, 16401740," Anuario Instituto de Estudios Histórico Sociales (en adelante citado como IEHS), no. 13 (1998); M. B. Gentile, D. Suárez, y J. Quintar, "Chilenos y argentinos en la frontera nordpatagónica: Un análisis historiográfico y nuevas perspectivas," Revista de estudios transandinos, no. 2 (julio 1998); y C. A. Mayo, "La frontera: Cotidianidad, vida privada e identidad," en Historia de la vida privada en la Argentina, ed. F. Devoto y M. Madero, vol. 1 (Buenos Aires: Taurus, 1999).

${ }^{11}$ D. J. Santamaría y J. A. Peire, "Guerra o comercio pacífico? La problemática interétnica del Chaco centrooccidental en el siglo XVIII," Anuario de estudios americanos 50, no. 2 (1993); D. J. Santamaría, “Apostatas y forajidos: Los sectores sociales no controlados en el Chaco, siglo XVIII," en Pasado y presente de un
} 
ámbitos de encuentro y desencuentro y donde distintos agentes situados a distintas escalas, a través de sus prácticas y representaciones definen el lugar ${ }^{12}$ de la frontera. ${ }^{13}$

Hacia la segunda mitad del siglo XVIII, en su afán de conservar sus territorios de ultramar la Corona Hispánica en manos de la dinastía borbónica, intensificó su presencia en los territorios de América Meridional. ${ }^{14}$ Es en este contexto que inició la ocupación de la costa atlántica patagónica. Las propuestas de avance de la frontera tuvieron en la mira las prácticas y representaciones que desde el mundo hispánico se tejían de las acciones de las pretensiones inglesas y francesas en el área y de las prácticas de las poblaciones indígenas que las habitaban.

El objetivo de este trabajo es analizar algunas de las acciones realizadas por la Corona Hispánica a fin de avanzar en la ocupación de la Patagonia hacia mediados del siglo XVIII y defender dichos ámbitos de la posible penetración inglesa. La política borbónica se orientó a la organización de los llamados establecimientos, especie de factorías, en la costa Atlántica Sur de América Meridional. La propuesta original era incentivar la ocupación de los mismos con población peninsular, proyecto que fracasó frente a las dificultades climáticas y de organización de los propios asentamientos. Los

mundo postergado: Estudios de antropología, historia y arqueología del Chaco y piedemonte surandino, comp. A. Teruel y O. Jerez (Argentina: Universidad Nacional de Jujuy, Unidad de Investigación en Historia Regional, 1998); y S. Ratto, "Relaciones fronterizas en la Provincia de Buenos Aires," Etnohistoria (1999); http://www.naya.org.ar/etnohistoria/.

${ }^{12}$ Seguimos la acepción de lugar de J. Agnew, Place and Politics: The Geographical Mediation of State and Society (Londres: Allen \& Unwin, 1987), para quien este concepto combina la idea de distribución espacial y económica de las actividades, las interacciones asociadas a la vida diaria y la identificación generada por la vivencia en él.

${ }^{13}$ D. Newman, "Transforming Ethnic Frontiers of Conflict into Political Frontiers of Peace," en Ethnic Frontiers and Peripheries, ed. O. Yiftachel y A. Meir (Boulder, Co.: Westview, 1998); J. Martins de Souza, "O tempo da fronteira: Retorno à controvérsia sobre o tempo histórico da frente de expansão e da frente pioneira," Tempo social 8, no. 1 (mayo 1996): 25-70; C. Hevilla, "El estado innovador: Estrategias de control y contacto en la frontera," Scripta Nova: Revista electrónica de geografía y ciencias sociales, no. 125 (2000); http://www.ub.es/geocrit/b3w-125; C. Barros y P. Zusman, "Hybridity and the Constitution of Places," en Travelling Concepts I: Text, Subjectivity and Hybridity, ed. J. Goggin y S. Neef (Amsterdam: ASCA, 2000); y C. Hevilla, "Fiesta, migración y frontera," III Coloquio Internacional de Geocrítica: Migración y cambio social, 2001; http://www.ub.es/geocrit/c3-hev.htm.

${ }^{14}$ A. Pagden, Señores de todo el mundo: Ideologías del Imperio en España, Inglaterra y Francia en los siglos XVI, XVII y XVIII (Barcelona: Península, 1997); J. Lynch, El siglo XVIII (Barcelona: Crítica, 1991); O. Gil Munilla, “El Río de la Plata en la política internacional: Génesis del Virreinato,” Cuadernos de la Escuela de Estudios Hispanoamericanos, no. 54 (1949); y O. R. Nocetti y L. B. Mir, La disputa por la tierra: Tucumán, Río de la Plata y Chile, 1531-1822 (Buenos Aires: Sudamericana, 1997). 
establecimientos actuaron como lugar de contacto privilegiado de la población hispánica con las sociedades indígenas y su mantenimiento o desalojo se ligó al proyecto de vincularlos a las líneas de fortines existentes en la campaña bonaerense.

A lo largo de más de cuatro siglos y, a partir de sus características físicas y poblacionales, se han construido diversas representaciones geográficas ${ }^{15}$ en torno de la Patagonia que van desde aquellas que la presentan como una tierra paradisíaca hasta aquellas otras que la describen como un ámbito hostil para su ocupación. No sólo sus características materiales como las representaciones discursivas provenientes de ámbitos tan dispares como el del conocimiento científico, de la escuela, del turismo, del propio estado han convergido en la constitución de un lugar que aun hoy se encuentra envuelto en cierto flaneur de exotismo. Ya el mismo nombre Patagonia habla de los mitos iniciales tejidos en torno a su exploración. Así el relato de Antonio Pigaffetta, cronista italiano que acompañó a Magallanes por su viaje al Mar del Sur (1520) consigna que dicho explorador consideró a los habitantes nativos un pueblo de gigantes y les dio el nombre de Patagones. Dicho nombre puede estar asociado a ciertas imágenes que aparecían en textos medievales, en libros de caballería, referidos a la llegada de héroes a tierras hasta entonces desconocidas por el mundo europeo y su encuentro con aborígenes destacados por su corpulencia. Más aún, en uno de dichos relatos de caballería, Palmerín de Oliva (1511), de autor anónimo, aparece el nombre de Patagón dado al gigante que vivía en un pueblo ficticio. ${ }^{16}$

La Patagonia jugó un papel importante en la definición de la modernidad imperial. ${ }^{17} \mathrm{El}$ mismo viaje de Magallanes y el descubrimiento europeo del estrecho que hoy lleva su nombre, significó para el viejo continente la posibilidad de contar con un medio de comunicación entre ambos océanos, iniciándose así un nuevo orden económico espacial. La Patagonia también estuvo involucrada en la producción de las pautas modernas de conocimiento que incorporan tanto la historia como la naturaleza, siendo el viaje de Darwin en el Beagle (1831-1836) una muestra de ello. Ya en el período de formación del Estado argentino, confluyeron en torno a este ámbito geográfico un conjunto de narrativas e imágenes estatales para mostrar su importancia en la constitución del territorio. Así, la idea de desierto fue una de aquellas metáforas que lo mostraron como

\footnotetext{
${ }_{16}^{15}$ D. Gregory, Geographical Imaginations (Londres: Blackwell, 1995).

${ }^{16}$ M. T. Luiz y M. Schillat, La frontera austral: Tierra del Fuego, 1520-1920 (Cádiz: Universidad de Cádiz, Servicio de Publicaciones, 1997), 70-1.

${ }^{17}$ G. Nouzeilles, "Patagonia as Borderland: Nature, Culture and the Idea of Sate," Journal of Latin American Cultural Studies 8, no. 1 (1999): 35-48.
} 
un área bajo dominio indígena, ${ }^{18}$ infértil por estar habitado por este tipo de poblaciones y que esperaba la mano del hombre blanco, inmigrante y trabajador para dar todo de sí. ${ }^{19}$ En diferentes coyunturas del siglo XX el Estado Nación hizo de este ámbito territorial un componente clave de la comunidad imaginada argentina, tendiente a lograr la unidad de los habitantes por encima de las crisis económicas, la represión y las desigualdades sociales. En este marco, los discursos políticos de poblamiento de la Patagonia, o de defensa contra las posibles pretensiones del Estado chileno, ${ }^{20}$ se asociaron a políticas de colonización y al incentivo industrial. $^{21}$

Aproximarse a la historia territorial de la ocupación patagónica en el siglo XVIII permitirá entonces comprender las bases materiales y representacionales que llevaron al pasaje de una tierra res nullius a la definición de la frontera colonial patagónica. Proponemos realizar este tipo de abordaje a partir de una concepción no turneriana de avance de frontera sino que tome como punto de partida formas de constitución de frontera vigentes en la época.

\section{Turner y la reinterpretación de la frontera colonial a la luz de los procesos medievales europeos}

\footnotetext{
${ }^{18}$ P. Zusman, "Civilization, Progress and 'Gran Chaco's Geography': A Territorial Approach to the Political Project for the Formation of Argentine-State," en Religion, Ideology and Geographical Thought, ed. U. Wardenga y W. Wilcynsky (Kielce: Institu Geografii and IGU Comission on the History of Geographical Thought, 1998); y C. Lois, "La invención del desierto chaqueño: Una aproximación a las formas de apropiación simbólica de los territorios del Chaco en los tiempos de formación y consolidación del Estado Nación argentino," Scripta Nova: Revista electrónica de geografía y ciencias sociales, no. 38 (1999); http://www.ub.es/geocrit/sn-38.htm.

${ }^{19}$ P. Navarro Floria, Ciencia y política en la región nordpatagónica: El ciclo fundador, 1779-1806 (Temuco: Universidad de la Frontera, Departamento de Humanidades, 1994); Idem, "Un país sin indios: La imagen de la Pampa y la Patagonia en la geografía del naciente estado argentino," Scripta Nova: Revista electrónica de geografia y ciencias sociales, no. 51 (1999); http:www.ub.es/geocrit/sn-51htm.

${ }^{20}$ R. Rey Balmaceda, Geografía histórica de la Patagonia, 1870-1960 (Buenos Aires: Cervantes, 1976); Idem, Límites y fronteras (Buenos Aires: Oikos, 1979).

${ }^{21}$ Pablo J. Cicolella, "Reestructuración industrial y transformaciones territoriales," Territorio: revista para la producción y crítica en geografía y ciencias sociales, no. 4 (1993).
} 
El trabajo de Frederick J. Turner sobre "El significado de la frontera en la historia de América",22 ha sido el que más repercusión ha tenido entre los historiadores y geógrafos para tematizar el proceso de constitución de la frontera colonial hispánica en América Septentrional $^{23}$ y en América Meridional. ${ }^{24}$

Turner construyó una interpretación de la historia norteamericana, sobre un patrón epistemológico biologicista. Destacó la relevancia de la supuesta existencia de tierras libres y el avance de los pioneers sobre la misma como base del nacionalismo democrático norteamericano.

Más allá de las críticas a la formulación de la teoría turneriana, ${ }^{25}$ su aplicación a este tipo de contextos ${ }^{26}$ aunque sea despojada del carácter nacionalista contenida en la misma resulta extemporánea, teniendo en cuenta particularmente que existen procesos europeos

\footnotetext{
${ }^{22}$ F. J. Turner, "El significado de la frontera en la historia americana," en Estudios (nuevos y viejos). La primera edición del texto de Turner se hizo en 1893.

${ }^{23}$ D. Weber, "Turner, los boltonianos y las tierras de la frontera," en Estudios (nuevos y viejos); y A. L. Hurtado, "Parkmanizing the Spanish Borderlands: Bolton, Turner and the Historians World," Western Historical Quarterly 26 (1995): 149-67.

${ }^{24}$ C. Mayo, "Sociedad rural y militarización de la frontera en Buenos Aires, 1737-1810," Jarbuch fur Geschichte von Staat Wirtschaft und Gesellschaft Lateinamerikas, no. 24 (1987); H. Clementi, Una clave interpretativa de la historia americana, vol. 1 de La frontera en América (Buenos Aires: Leviatán, 1992); y M. B. Vitar Mudski, Guerra y misiones en la frontera chaqueña del Tucumán, 1700-1767 (Madrid: Consejo Superior de Investigaciones Científicas, 1997).

${ }^{25}$ Ver Carl O. Sauer, "Historical Geography and the Western Frontier," en Land and life: A Selection from the Writings of Carl Sauer, ed. J. Leighly (1929; California: Berkeley University of California, 1963); J. F. Bannon, The Spanish Borderlands Frontier, 1513-1821 (Albunquerque: University of New Mexico Press, 1990); y J. Varela Ortega, "Un siglo después de Turner: Conquistados por el oeste," Revista de Occidente, no. 152 (enero 1994). Los estudios de frontera despertaron el interés de los geógrafos culturales que buscaron romper con el determinismo turneriano. Así, por ejemplo, en el artículo de Carl Sauer "Historical Geography and the Western Frontier" (1929) la frontera pasa a ser un laboratorio de estudio del cambio de un paisaje natural a cultural, poniendo cierto énfasis en los agentes que participan en dicho proceso. Sauer destaca que ni existe un único tipo de frontera, ni existen una serie uniforme de estadios por los que debería pasar la frontera; ello varía según las características físicas del país, según la "civilización" que se ha desarrollado en ella, y según el momento histórico (Sauer, "Historical Geography," 49). Otro geógrafo, Owen Lattimore sostiene que en su preocupación por estudiar qué es lo que la frontera provocó en la sociedad, Turner no toma en cuenta lo que esta sociedad produjo en la frontera (citado en M. Mikesell, "Comparative Studies in Frontier History," Annals of the Association of American Geographers, no. 50 [1960], 64.

${ }^{26}$ S. Zavala, "Las fronteras en Hispanoamérica," Cuadernos hispanoamericanos, no. 100 (julio-octubre 1958); y D. Gerhard, "The Frontier in a Comparative View," Comparative Studies in Society and History 1 (marzo 1959).
} 
medievales que hablan también del avance sobre la frontera y que debieron actuar de fuentes inspiradoras de las acciones realizadas por la Corona Hispánica en sus territorios de ultramar. Además, la interpretación turneriana no da cuenta del tipo de relaciones que el encuentro de sociedades distintas provocó en el lugar de la frontera.

En este sentido, el proceso de avance de ocupación de los reinos cristianos de territorios en manos de reinos musulmanes en la península ibérica merece una particular atención. En este contexto, se fueron definiendo ciertos lugares con particularidades de áreas de frontera. Un ejemplo de ello es la alta Meseta del Duero. Villar García caracteriza esta área como de "interposición" para las pretensiones intervencionistas cristianas o musulmanas entre el naciente reino Astur y los territorios de Al-Andalús, viéndose asolada por las expediciones musulmanas de la conquista, raziada por las correrías de los primeros reyes astures, arruinada por el abandono de parte de sus pobladores y de sus cuadros administrativos. Para este autor la historia de la Meseta del Duero hasta el siglo XI no es ni cristiana ni musulmana, no pertenece ni se integra en ninguno de los dos marcos político-administrativos que se enfrentan en la península. Sus pocos y desarticulados habitantes, fijan sus asentamientos y regulan su modo de vida de acuerdo con las relaciones y situaciones del reino Astur-leonés y Al-Andalus. Más allá de la presentación de la Meseta del Duero como vía de paso, ella se muestra como un ámbito híbrido, integrado nominal (desde la representación) y políticamente (en tanto espacio de reivindicación) a los ámbitos de poder de los reinos Astur-leonés y Al-Andalus. ${ }^{27}$

En realidad, las fronteras entre el mundo cristiano y el musulmán en la península ibérica fueron lugares de encuentro y desencuentro. Por ejemplo entre los años 1350 y 1460 , transcurrieron 25 años de guerra "oficial" y 85 de paz a través de firmas de tratados también oficiales. Esta situación implicaba una relación entre ambos mundos que significó la colaboración y una marcada aculturación. ${ }^{28}$

Las alianzas entre sultanes y reyes cristianos eran habituales. Los acuerdos firmados se referían a temas tales como: intercambio de prisioneros, el comercio y la resolución de problemas fronterizos. Eran usuales también los acuerdos orales a fin de dejar pastar a

\footnotetext{
${ }^{27}$ L. M. Villar García, La Extremadura castellano-leonesa: Guerreros, clérigos y campesinos, 711-1252 (Valladolid: Junta de Castilla y León, Consejería de Educación y Cultura, 1986).

${ }^{28}$ A. Mackay, "Religion, Culture and Ideology on the Late Medieval Castilian-Granadian Frontier," en Medieval Frontier Societies, ed. R. Bartlett y A. Mackay (Oxford: Clarendon, 1989), 217.
} 
los ganados de cristianos en los territorios bajo dominio musulmán. ${ }^{29}$ Cabe destacar también que a pesar de las prohibiciones y controles, el contrabando estaba bastante extendido en la frontera.

Prácticas de intercambio, de alianza junto a acciones ofensivas y defensivas fueron constitutivas de las relaciones entre los reinos cristianos y musulmanes hasta la toma de Granada en 1492 por la Corona de Castilla. Este tipo de prácticas son reconocidas también en las acciones desarrolladas por los españoles con las poblaciones indígenas en el mundo colonial y, en el caso del avance de la frontera patagónica, en particular.

\section{Los establecimientos patagónicos como estrategia de avance de la frontera colonial (1778-1792)}

El territorio conocido como Patagónico ha sido el área de América Meridional de más tardía apropiación por parte de la Corona Hispánica. Los antecedentes de su reconocimiento se remontan al siglo XVI, inspirados por un lado en el imaginario geográfico de la existencia de grandes masas continentales en el sur que actuaban como contrapeso de los continentes del hemisferio norte, las Terras Australis, por un lado y por el otro en la búsqueda de una nueva forma de comunicación entre el Pacífico y el Atlántico.

Será la coyuntura internacional provocada principalmente por los resultados de la reorganización territorial colonial americana posterior a la Guerra de los Siete Años (1756-1763) la que estimulará el reconocimiento y apropiación de la región austral de América Meridional por parte de los ingleses y franceses. Inglaterra había triunfado sobre España en los últimos meses de la guerra y en Canadá logró derrotar definitivamente a los franceses aliados de los españoles por el III Pacto de Familia. Ocupó la Luisiana Oriental y la Florida, obtuvo las islas de Granada, San Vicente, Dominica y Tobago. Atacó y rindió a los españoles en La Habana, devolviéndosela luego. El tratado de París (1763) marcó así el inicio de la hegemonía mundial inglesa que comenzaría a plantearse nuevas metas. Por su parte Francia, que había perdido prácticamente todas sus colonias en América del Norte, -Canadá, Acadia, Isla del Cabo Bretón y territorios situados al oeste del Mississipi- y la hegemonía en la India, buscaría una compensación de estas pérdidas en términos territoriales y económicos.

29 J. E. López de Coca Castañer, "Castilian-Granadan Frontier Institutions," en Medieval Frontier Societies, 132-42. 
Desde entonces las coronas inglesa y francesa iniciaron una serie de actividades exploratorias que pusieron en aviso a la propia metrópoli ibérica de la necesidad de reconocimiento y ocupación de las tierras de la Patagonia sudoriental. A su vez, el Tratado de París dio cuenta de la pérdida de legitimidad de los principios papales como único criterio jurídico que apoyaba la defensa de estas colonias como posesión hispánica y la preeminencia del criterio de reconocimiento y ocupación defendido por la corona inglesa y francesa. Esta última argumentación permitía entonces que los territorios patagónicos fueran considerados res nullius, es decir, tierra de nadie. Pero el criterio de res nullius pierde sentido si pensamos que diferentes agrupaciones indígenas habitaban en los mismos, parcialidades que justamente, serán contempladas en los proyectos territoriales coloniales como sujetos a ser cooptados para poder asegurar el control sobre los pretendidos ámbitos geográficos de dominación.

\section{A. La instrucción de Floridablanca}

El levantamiento de las colonias en América Septentrional y el temor de que los ingleses buscaran nuevas áreas destinadas al desarrollo del comercio (hipótesis de mínima) o de apropiarse de los ámbitos bajo dominio hispánico (hipótesis de máxima) promovieron la decisión hispánica de erigir un conjunto de establecimientos ${ }^{30}$ en la costa patagónica.

\footnotetext{
${ }^{30}$ El relato de un funcionario del establecimiento de San Julián nos da cuenta de las características de los mismos. San Julián contaba con "Un fuerte de madera de veinte y ocho varas en cuadro con sus habitaciones dentro, para la plana mayor, maestranza, cuarteles de tropa, y almacenes. Un hospital de veinte y cuatro varas sito al sur del fuerte... Inmediato a esta fábrica, sita otra, con su frente a la plaza se extiende al Norte, setenta y dos varas, sirve de habitaciones a los pobladores dividida en nueve casas, que ocupan otras tantas familias, de a ocho varas de frente, y seis de luz, con su sala y dormitorio, sus techos, paredes, maderas, ventanas y rejas en todo como la anterior. A lado opuesto del fuerte, sita otra que consta de cuarenta, y una varas extendiéndose como la anterior y su distribución, en una panadería... una herrería de trece varas... Contiguo a esta fábrica se halla un corral para custodia del ganado de treinta y seis varas de frente, y cuarenta y una de fondo sus paredes de tapial de una vara de grueso y tres de altura. Con inmediación a la anterior fábrica, dejando su calle en medio de once varas, y su extensión al propio vento formando el otro frente de la plaza, se halla obrando la segunda cuadra que había de servir de habitaciones a los pobladores, y consta de las setenta y dos varas, distribuidas en las nueve casas, en ella se ven levantadas sus paredes, y mojinetes de adobe crudo, lo que corresponde a seis de las nueve casas." Simón de la Puente, Guarda Almacén y Contador Tesorero Interino del Establecimiento de San Julián, 29 de enero de 1784, Archivo General de Indias, Sevilla, Gobierno, Audiencia de Buenos Aires, 99.
} 
Floridablanca, secretario de Estado de Carlos III (1759-1788) justificaba esta necesidad en la suposición que los ingleses buscarían llegar a los centros más importantes del Imperio en la zona:

Cualquier establecimiento que hagan en las Costas de la América Meridional, debe ser indefectiblemente muy perjudicial para la seguridad de los nuestros, y para nuestra navegación en aquellos mares, siendo de recelar se sitúen en algún paraje de la parte que corre desde el Río de la Plata hasta el Estrecho de Magallanes, y aún en el estrecho mismo. Por consiguiente es de la mayor importancia procedamos sin pérdida de tiempo a ocupar allí algunos puntos esenciales que impidan cualquier tentativa, precaviendo los graves daños que se nos seguirían de que se adelantasen los Ingleses a ocupar dichos puestos, desde donde interceptarían fácilmente nuestra navegación por el Cabo de Hornos, internándose en el Reino de Chile hasta invadir el Perú. ${ }^{31}$

Para poder entonces, interceptar estas naves que quieran llevar adelante esta ruta de navegación del Atlántico sur hacia el Pacífico sur, Floridablanca propone la organización de dos establecimientos en la costa atlántica patagónica:

Dos son los parajes principales adonde debemos desde luego dirigir nuestro conato para ocuparlos inmediatamente y formar en ellos alguna población que después se perfeccione y nos sirva también de escala para adelantar nuestros reconocimientos, la Bahía Sin $\underline{\text { Fondo, }}$ y la Bahía de San Julián. ${ }^{32}$

La elección de ambos "parajes" es justificada en la misma instrucción: La Bahía Sin Fondo era el punto de desembocadura del Río Negro y era visualizada como posible vía de penetración al Reino de Chile. Por su lado, la Bahía de San Julián, más próxima a las Malvinas ${ }^{33}$ podría socorrer a cualquier expedición destinada a dichas Islas. Subalterno al

\footnotetext{
${ }^{31}$ Instrucción de Floridablanca sobre organización de los establecimientos en Patagonia, 8 de mayo de 1778, Audiencia de Buenos Aires, 326. Las citas de los documentos han sido adecuadas a las formas de escritura actual para facilitar la comprensión del presente texto.

${ }^{32}$ Ibid. Los subrayados corresponden al original.

${ }^{33}$ En realidad el proceso de ocupación patagónico estuvo incentivado por las primeras ocupaciones francesas e inglesas a las Islas Malvinas. El primer asentamiento en el lugar fue organizado por los franceses: ellos fundaron el establecimiento de Port Louis, que abandonarían más tarde luego de recibir la indemnización de la Corona Española. Por su lado los ingleses se establecieron en Puerto Egmont, actual Gran Malvina. Hasta 1774, momento en que fueron desalojados, la población inglesa convivió con la española de Nuestra Señora de la Soledad, combinación de establecimiento militar y presidio, creado en el mismo lugar en que los franceses habían organizado Port Louis, en la actual isla Soledad. O. Gil Munilla, Malvinas: El conflicto anglo-español de 1770 (Sevilla: Escuela de Estudios Hispano-americanos, 1948).
} 
establecimiento de Sin Fondo se proponía la organización de un Fuerte en el Río Colorado, considerado también vía de penetración a Chile e instrumento de defensa de las salinas que se hallaban en dicho lugar. Del establecimiento de San Julián dependería el Fuerte de Puerto Deseado. ${ }^{34}$

\section{B. La política de colonización}

La instrucción de Floridablanca de 1778 preveía el poblamiento de los establecimientos patagónicos con familias peninsulares. Ello significaba una ruptura con las teorías ilustradas según las cuales, la emigración era considerada un claro motivo de debilitamiento de un país. Por este motivo, hasta este momento, las cortes europeas habían procurado atraer pobladores extranjeros como medida para incentivar el desarrollo de sus reinos. ${ }^{35}$ Sin embargo, en el contexto en que las relaciones con los ingleses se hallaban en estado candente, posiblemente, la presencia de población no peninsular en los territorios de la costa Atlántica Sudoriental sería percibida más como una manera de aumentar la vulnerabilidad del área que como un medio de fortalecerla. Si se temía una posible alianza de los ingleses con la población indígena, podía ser todavía más previsible el pasaje de información o la obtención de apoyo por parte de población no hispánica a cualquiera de las expediciones enviadas al Atlántico Sur por las metrópolis deseosas de asentarse en el área.

El proyecto de colonización de estos establecimientos con población ajena al área encontraba en varios aspectos su fuente de inspiración en la experiencia del traslado de alemanes en la Sierra Morena, realizada en tiempos de Carlos III y en experiencias americanas como las de Chile (1711) y Cuyo (1755). Una de las semejanzas de esta

\footnotetext{
${ }^{34}$ En la Bahía Sin Fondo (actualmente península de Valdés) se estableció el Fuerte de San José. Francisco de Viedma exploró la desembocadura del Río Negro y estableció aguas arriba una población sobre su margen derecha, una creciente obligó a trasladar esta población a una terraza elevada ubicada sobre la margen izquierda del curso fluvial. En este sitio se emplazó la población y fuerte de Nuestra Señora del Carmen. Luiz y Schillat, La frontera austral, 50.

${ }^{35}$ Por ejemplo, Prusia, con Federico II, experimentó un proceso de colonización interna en la zona oriental y Pomerania; Austria, bajo María Teresa y José II, contempló la inmigración de suavos para colonizar los territorios del sureste; en Rusia, con Catalina II, se produjo un asentamiento de campesinos alemanes a orillas del Volga; los ingleses, enviaron alemanes y suizos a sus colonias de Norteamérica; los franceses pensaron implantar, en Haití, un sistema de colonizaciones basadas en el establecimiento de bucaneros, los propios españoles estudiaron la posibilidad de asentar colonos franceses en Trinidad. J. M. Porro Gutiérrez, La emigración asturiana y castellano-leonesa para el poblamiento de la Patagonia en época de Carlos III (Valladolid, 1995), 11-12.
} 
propuesta de colonización con la de Sierra Morena fue la adscripción a la tierra como sistema de población. Ello no suponía ni la obtención de ningún titulo nobiliario, ni la categoría de vecino ni algún tipo de exención fiscal o privilegio de las cuales habían sido acreedores por ejemplo la población fundadora de Montevideo. A través de la firma de $\operatorname{contratas}^{36}$ se les ofrecía habitaciones, útiles para la labor y tierras en propiedad, una ó dos yuntas para su beneficio, semillas para sembrar y se les mantendría económicamente por el plazo de un año, contado desde que el Virrey estipulara su destino a dichos establecimientos. El hecho de que en las contratas no se estableciera cuándo se les haría entrega de las tierras en carácter de propiedad ni dejaran espacio para una vuelta al lugar de origen, suponía, por un lado, una forma de migración distanciada de la estrategia golondrina practicada en la época y, a su vez, un desestímulo para las poblaciones peninsulares a la posibilidad de embarcarse en este proyecto político.

Durante el período en que se mantuvo el proyecto de formación de colonias con población peninsular (1778-1784) pasaron al Río de la Plata alrededor de 2,028 personas. ${ }^{37}$ Las familias fueron destinadas a los cuatro establecimientos siguientes:

- Fuerte y Puerto de San José. A este establecimiento llegaron nuevos pobladores en 1778. Subsistió hasta agosto de 1810 , fecha en que fue destruido por un ataque indígena

- Fuerte de Nuestra Señora del Carmen y Pueblo de Nueva Murcia. En octubre de 1779 llegaron los primeros pobladores gallegos. Fue el único establecimiento que perduró hasta la actualidad con el nombre de Carmen de Patagones

- Castillos de Todos los Santos y San Carlos, Puerto Deseado. Su vida fue corta. Se erigió en 1780 y fue desmantelado en agosto de 1781

- Nueva Población y Fuerte de Floridablanca, Puerto de San Julián: fue organizado en enero de 1781 y fue mantenido hasta enero de 1784

Según el proyecto de colonización, las poblaciones patagónicas quedaban a cargo del comisario superintendente, funcionario con atribuciones semejantes a las otorgadas al superintendente de Sierra Morena. Al igual que este último, el comisario superintendente, era designado por la Corona, aunque quedaba subordinado primero al virrey. En el caso de la Bahía Sin Fondo se designó como Comisario Superintendente a

\footnotetext{
${ }^{36}$ Se llamaba así al documento por el cual se fijaban las condiciones que la Corona otorgaba a los que se inscribieran en el llamamiento para emigrar al Río de la Plata y las obligaciones a los que ellos quedaban sujetos.

${ }^{37}$ Porro, La emigración asturiana, 43.
} 
Francisco de Viedma y en el de San Julián a Juan de la Piedra, reemplazado luego por Antonio de Viedma. ${ }^{38}$

Las condiciones climáticas, la precariedad de infraestructura y la situación sanitaria de las nuevas poblaciones, así como los vaivenes de la política metropolitana con relación al mantenimiento o abandono de estos establecimientos, explican que gran parte de la población traída de España se asentara no en la Patagonia sino en el Río de la Plata, especialmente en la campaña de Buenos Aires y en villas situadas entre las localidades de Colonia y Maldonado.

\section{La relación con la población indígena}

A través de distintas exploraciones y relatos de viajeros la monarquía hispánica tuvo conocimiento del tipo de poblaciones que habitaban la Patagonia así como su localización. Por ejemplo, la exploración realizada por uno de los responsables de los establecimientos, Antonio de Viedma, reconoció 4,000 indígenas habitando la costa meridional patagónica desde los $44^{\circ}$ latitud sur (Puerto de Santa Elena) hasta los $52^{\circ}$ (Cabo de las Vírgenes) y describió los dominios de determinados caciques:

Puerto de Santa Elena es bueno para todo género de embarcaciones esta en los 44 grados de latitud... El cacique que habita aquellos terrenos se llama Ayso, es su jurisdicción hasta el Puerto de San Gregorio... Puerto de San Gregorio que está a los 45 grados 4 minutos de Latitud. El cacique que lo habita se llama Gorgona... El Golfo de San Jorge está al Sur del Cabo de Matas que es la latitud de San Gregorio desde donde empieza su boca hasta Cabo Blanco son 50 leguas... La costa del Sur del Golfo dicen es más estéril que la del Norte. Los caciques que lo habitan, se llama el uno Chayguas, y el otro Enes, ambos hermanos. Puerto Deseado que está a los 47 grados 48 minutos latitud es bueno, pero de muy difícil entrada por ser la boca estrecha, y de muy violentas corrientes... El cacique que ocupa este terreno se llama Ulquicuenque... El Puerto de San Julián... El cacique que habita este terreno desde Puerto Deseado hasta el Río de Sta. Cruz se llama Camelo, y nosotros le llamábamos Julián, es de los de más séquito en su nación un cuñado suyo llamado Onos lo tiene como su subalterno y habita los terrenos de las Lagunas de Sta. Cruz. A las quince leguas del Río de Sta. Cruz al Sur hay otro arroyo nacido de las nieves de la cordillera que por aquel paraje va ya cerrando hacia el Estrecho de Magallanes... A los 52 grados Latitud Sur está el Cabo de las Vírgenes, y comienza el Estrecho de Magallanes cerrándose la cordillera al medio del Estrecho, y dicen los Indios es inaccesible para pasar por tierra al

\footnotetext{
${ }^{8}$ Carlos M. Gorla, Los establecimientos españoles en la Patagonia: Estudio institucional (Sevilla: Escuela de Estudios Hispano-americanos, 1984), 40.
} 
otro lado. El cacique que habita aquellos terrenos se llama Coopan, es de los que tienen más Indios, pero todos son de a pie. ${ }^{39}$

Según los estudios de etnografía histórica de Lidia Nacuzzi (1998) referidos al área, cada cacique tenía jurisdicción sobre territorios perfectamente deslindados, con pautas de tránsito y de utilización de los paraderos ubicados en territorios ajenos. Las alianzas y los movimientos se orientaban a acceder a la frontera de Buenos Aires y principalmente al ganado cimarrón. El tipo de asentamiento, definible por la cantidad de toldos y el tiempo en que permanecían en algún paraje, estaba condicionado por la finalidad de los movimientos: caza, comercio, aprovisionamiento de otros recursos y relaciones políticas.

Es posible hablar de una "división del trabajo" en el área vinculada a una supuesta diferenciación de grupos étnicos: los llamados por los españoles aucas, localizados próximos a la cordillera aportaban ponchos y productos agrícolas; los pampas y aucas que se relacionaban con el Fuerte del Carmen se especializaban en el manejo de ganados y los denominados tehuelches del sur del río Negro se dedicaban a la obtención de pieles. $^{40}$

El conocimiento de las dinámicas indígenas sirvió a los españoles para plantear políticamente el tipo de acciones a desarrollar con estas poblaciones. En general, la política borbónica priorizó las prácticas de alianzas sobre las acciones ofensivas. ${ }^{41}$ Esto adquirió características específicas en áreas como la patagónica en donde la propuesta de negociación fue leída también como una forma de contar con el apoyo de las poblaciones locales en el momento en que los ingleses decidieran penetrar en el interior del continente, práctica que también los ingleses llevaban adelante en los territorios coloniales bajo su dominio o que ellos pretendían dominar. Pero estas alianzas también tenían el objetivo de entrar en el campo interétnico y establecer vínculos con otros grupos, a favor de los españoles.

\footnotetext{
${ }^{39}$ Descripción de la Costa Meridional Patagónica de Antonio de Viedma, Buenos Aires, 10 de diciembre de 1783, Audiencia de Buenos Aires, 99.

${ }^{40}$ L. R. Nacuzzi, Identidades impuestas: Tehuelches, aucas y pampas en el norte de la Patagonia (Buenos Aires: Sociedad Argentina de Antropología, 1998), 249.

${ }^{41}$ D. Weber, "Borbones y bárbaros: Centro y periferia en la reformulación de la política de España hacia los indígenas no sometidos," Anuario IEHS, no. 13 (1998); y G. Wilde, “¿Segregación o asimilación? La política indiana en América Meridional a fines del período colonial," Revista de Indias 59 (1999): 217.
} 
Y teniendo los indios de San Julián comercio con los indios que median, en las distancias del Cabo de las Vírgenes, Puerto de la Hambre, y tierras del Golfo de San Jorge, se facilita las noticias de estos, y de todo el Estrecho, para ocurrir con tiempo, a cualquiera tentativa que los Extranjeros pensasen hacer, sobre establecerse en aquellos puertos. ${ }^{42}$

Como decíamos antes, existían antecedentes respecto a la búsqueda de establecimiento de alianzas entre poblaciones indígenas y los representantes de otras potencias coloniales como camino para controlar territorio hasta entonces bajo dominio hispánico. Por ejemplo, los ingleses habían construido vínculos con los indios mosquitos para desarrollar la explotación maderera en la desembocadura del Río Tinto en América Central (1675-1750). ${ }^{43}$ De la misma forma se habían concertado alianzas entre holandeses e indígenas en el sur de Chile en el siglo XVII, así como se había celebrado un contrato entre franceses e indígenas en el estrecho magallánico en $1766 .^{44}$

Dentro de este marco hacia los años de 1780 las autoridades situadas en el Río de la Plata entraron en negociaciones de paz con las poblaciones aborígenes situadas en el norte de la Patagonia. Pero más allá de la colaboración política, las autoridades españolas en el ámbito colonial esperaban otro tipo de apoyo en el "locus" de la frontera. En efecto, el funcionamiento de la economía de los enclaves coloniales dependió en gran medida de la interrelación con los grupos nómadas que habitaban en la región. El conocimiento del interior del territorio, que estuvo casi vedado a los blancos hasta la llamada Conquista del Desierto (1879) organizada por el Estado argentino, fue quizás la principal fuente de poder para los grupos indígenas. Ellos conocían a la perfección la topografía, el clima, las aguadas y las rutas fáciles, lo cual les permitía obtener y trasladar ganado en pie con mucha eficacia, abastecerse de presas de caza, obtener recursos en parajes determinados, intercambiar productos con otros grupos vecinos. Las poblaciones hispánicas costeras estaban prácticamente aisladas, el aprovisionamiento de alimentos por vía marítima resultaba lento e incompleto. Ellos pasaron a depender de los indígenas en alimentos, en defensa y en contactos políticos. El fuerte de Carmen de Patagones, por ejemplo, adquiría de los indios ganado a cambio de harina, tabaco, aguardiente.

\footnotetext{
${ }^{42}$ Antonio de Viedma a Loreto, Buenos Aires, 10 de diciembre de 1783, Audiencia de Buenos Aires, 99.

${ }^{43}$ Alejandro S. Sagastume F., "Historia de una frontera olvidada: Establecimientos ingleses en Honduras," en Estudios (nuevos y viejos).

${ }^{44}$ Nocetti y Mir, disputa por la tierra, 220.
} 
El tipo de vínculo social y comercial cotidiano, que tenía en los establecimientos el lugar privilegiado de realización, se complementó con los efectos transculturales que estas relación adquirió para las propias poblaciones indígenas. De esta manera, se aceleraron los cambios que se venían esbozando en los grupos nativos desde los primeros contactos aislados en la costa y con el acceso a los ganados de la región pampeana y al caballo. Esto modificó las técnicas de caza, alimentación y la movilidad de estos pueblos. Con las colonias apareció el intercambio, el fácil acceso a bienes y alimentos que pronto se hicieron indispensables para los grupos indios. La presencia del blanco en la región significó el abandono de algunas pautas económicas, la adopción de otras, la mayor movilidad, la apropiación del ganado y el comercio como actividades casi excluyentes. ${ }^{45}$

\section{El conflicto por el mantenimiento o desalojo de los establecimientos patagónicos}

Hacia 1780 la corona hispánica se debatía entre la necesidad de mantener los establecimientos de la Patagonia tomando en cuenta el motivo que llevó a su erección y los costos que su mantenimiento significaban para el erario. Si bien las expectativas estaban puestas en la extracción de sal o en el desarrollo de la actividad pesquera cómo medios para lograr su subsistencia, hasta ese momento, ningún establecimiento estaba produciendo algún tipo de recurso que garantizase su autonomía. Por otro lado, el supuesto clima de disminución de las hostilidades con la Corona Inglesa llevaba a revisar la necesidad de mantener la acción defensiva en la región atlántica sudoriental. Los documentos muestran dos posturas claramente distantes. Mientras que el Virrey Vertiz (1778-1784), basado en informes de los Pilotos de la Real Armada Joseph Goycoechea, Juan Pascual Calleja y Bernardo Tafor se declaraba férreo partidario de su abandono y del mantenimiento de un único asentamiento, el de Nuestra Señora del Carmen, las personas que se desempeñaban como funcionarios en el área de frontera como eran el Comisario Superintendente Antonio de Viedma y el Piloto de la Armada

\footnotetext{
${ }^{45}$ Nacuzzi, Identidades impuestas, 249; R. Mandrini, "Las transformaciones de la economía indígena bonaerense, c. 1600-1820," en Huellas en la tierra: Indios, agricultores y hacendados en la Pampa bonaerense, comp. Raúl Mandrini y Andrea Reguera (Tandil: IEHS, 1993), 62.
} 
Real Basilio Villarino ${ }^{46}$ y Francisco de Viedma, ${ }^{47}$ se mostraron a favor de su preservación, acentuando en este sentido la importancia del Puerto de San José.

Mientras que las posturas de los subordinados de Antonio de Viedma ${ }^{48}$ que habían fundamentado la decisión de Vertiz acentuaban las dificultades físico climáticas para el abandono de los proyectos de colonización del área, tanto las visiones de los hermanos Viedma como de Villarino sostenían que el obstáculo geográfico debía ser salvado por las propias actividades humanas. ${ }^{49}$ Ello aparece expresado en uno de los documentos claves en defensa de la ocupación de la costa patagónica redactado por Francisco de Viedma donde se compara la situación climática y física patagónica con la de Suecia, Dinamarca o Rusia:

La latitud de 52 grados y medio al polo, aunque es clima muy frío, vemos que la Suecia, situación de Dinamarca, y Rusia le excede a mas de 70, y sus terrenos son fértiles, y abundantísimos. Querer sin el auxilio de ganados, sin el beneficio de la agricultura, sin la

\footnotetext{
${ }^{46}$ Basilio Villarino (1741-1785) nació en la Coruña. Fue piloto de la Armada Real. En el Río de la Plata se desempeñó en actividades de reconocimiento de los ríos Negro, Limay y colaboró en la fundación de Carmen de Patagones. En una exploración de reconocimiento de la región de Sierra de la Ventana muere a manos de los indios.

${ }^{47}$ Francisco de Viedma (1737-1809) nació en Jaén. Llegó al cargo de oficial naval. Integró la expedición enviada por el Virrey Vertiz, a la orden de Juan de la Piedra, para reconocer y establecer fuertes en el área de la Bahía Sin Fondo. En enero de 1779 fue dejado al mando de la guarnición en la Bahía de San José en Chubut. Realizó varios viajes exploratorios con Villarino en la región del Río Negro. Participó en la fundación de Carmen de Patagones. En 1785 es designado intendente de Santa Cruz de la Sierra. I. S. Wright y L. M. Nekhom, Diccionario histórico Argentino (Buenos Aires: Emecé, 1990).

${ }^{48}$ Los pilotos Callejas, Tafor y Goycoechea habían levantado diversos mapas correspondientes al Puerto Deseado, San Gregorio, Golfo de San Jorge, San Julián, y Santa Elena en las exploraciones que Antonio de Viedma hizo de la región sur de la costa patagónica. Archivo General de Indias, Catálogo de mapas y planos, catalogado por Pedro Torres Lanzas, vols. 1-2 (Madrid: Ministerio de Cultura, Dirección General de Bellas Artes y Archivos, 1988).

${ }^{49}$ En su informe a favor del sostenimiento de las poblaciones, Antonio de Viedma considera que las posturas que abogan por su abandono se fundamentan en la visión que los pilotos en cuestión tuvieron de las poblaciones y específicamente de San Julián al momento de elevar el informe, situación en la que imperaba el escorbuto, y donde las actividades agrícolas y ganaderas no habían comenzado a dar sus frutos. Para apoyar su informe Antonio de Viedma elabora un cuestionario que somete a 14 pobladores del establecimiento de San Julián donde se refuta la visión pesimista de las condiciones físicas y climáticas del área mostrando, además, el resultado positivo de las actividades agropecuarias emprendidas. El parecer del médico cirujano establecido en San Julián niega la existencia de una relación directa entre condiciones climáticas y brotes de escorbuto. Descripción de Antonio de Viedma de San Julián, San Julián, 10 de diciembre de 1783, Audiencia de Buenos Aires, 99.
} 
prueba de los experimentos arreglar, y perfeccionar la calidad de terrenos con conocimiento de su intemperie al uso de las labores, y efecto de sus producciones es tirar al blanco con los ojos cerrados. Los climas desiertos varían por el concurso de gentes y ganados, que componen una estable población: Con los fuegos, hálitos, y calor de los vivientes poco a poco se va templando la atmósfera, y produce en la tierra vapores, que le hacen más benigno, y le traen otra fertilidad. ${ }^{50}$

Pero el desarrollo de las argumentaciones en torno a la preservación o no de los establecimiento irían tomando otro cariz. Las mismas irían incorporando la posibilidad de que estas poblaciones fueran puntos de base para delinear la frontera a partir de ir ocupando terrenos en manos de la población indígena y permitiéndose así también la integración efectiva de los territorios de la costa patagónica al territorio bajo la jurisdicción del Virreinato del Río de la Plata.

\section{Los argumentos a favor del avance de la frontera colonial}

Como decíamos en el ítem anterior, Vertiz basaba su postura en la necesidad de "minorarse los gastos de los establecimientos patagónicos, atendidas las urgencias del real erario por la guerra y sucesos del Perú," ${ }^{, 1}$ frente al hecho que desde el punto de vista físico $\mathrm{y}$, según los informes recibidos, la costa meridional no presentaba ningún tipo de ventaja ni para ser habitada ni para ser económicamente explotada por "la calidad de sus terrenos, por falta de buenos puertos, por las excesivas mareas, por lo riguroso del clima y otras causas." 52

Villarino, por su lado, consideraba que "aquel raciocinio general sobre si puede o no importar al Estado la costa patagónica" conllevaría a dejar estos territorios al reconocimiento extranjero, de aquí que sostuviera que "no quisiera que ninguna extranjera en ningún tiempo tuviese la gloria de enseñarnos lo que nosotros debíamos saber." 53

\footnotetext{
${ }^{50}$ Disertación de Francisco de Viedma, 1 de mayo de 1784, Audiencia de Buenos Aires, 99.

${ }^{51}$ Vertiz se está refiriendo a las sublevaciones indígenas que tienen lugar en el Alto Perú entre $1780 \mathrm{y}$ 1783 y a la guerra de España con Inglaterra que culmina con la paz de Versalles (1783).

${ }^{52}$ Vertiz a Gálvez, Montevideo, 22 de febrero de 1783, Audiencia de Buenos Aires, 326.

${ }^{53}$ D. Basilio Villarino, Informe sobre los puertos de la costa patagónica Fuerte del Carmen del Río Negro, 19 de abril de 1782, Colección de obras y documentos relativos a la historia antigua y moderna de las provincias del Río de la Plata, comp. Pedro De Angelis (Buenos Aires: Plus Ultra, 1969), 5:228.
} 
El documento de Villarino mostraba una diferencia de perspectiva geoestratégica sustancial con el de Vertiz. Mientras que el Informe de Vertiz se limitaba a un análisis de la situación de los establecimientos en términos estrictamente locales y de las poblaciones entre sí, de su vínculo con la defensa estricta de la costa, el análisis de Villarino enfatizaba la importancia de las poblaciones patagónicas como vía de penetración interna para las potencias rivales, recuperando así el propósito inicial de organización de los establecimientos presente en la Instrucción de Floridablanca.

El contraste entre ambas posturas se refleja particularmente en la discusión sobre el mantenimiento o desalojo del Puerto de San José. Vertiz se mantuvo en la posición que las condiciones naturales hostiles del área y las dificultades de explotar la potencialidad en materia de sales que ofrecía la bahía eran fundamento suficiente para su abandono:

También deberá abandonarse... pues los gravísimos costos que tiene la saca y la conducción de la sal, sobre su desabrigo y aridez del terreno, hace inútiles lo que se empeñen en sostenerlos, y pudiera ser reconocido anualmente desde el río Negro. ${ }^{54}$

En contraposición Villarino veía al puerto de la Bahía de San José como un ámbito apto para la manutención de un establecimiento permanente:

Me parece que dejo suficientemente probado, que la naturaleza tiene auxiliado con el puerto de San José la entrada de este río a todos cuantos quieran venir en él y que no está defendida por ella: antes bien soy de sentir, y se evidencia de las razones expuestas... El puerto de San José no tiene inconveniente alguno para que deje de ser puerto de arribadas, y puedan refrescar las embarcaciones que allí arriben: allí pueden tenerse 2,000 y más cabezas de ganado vacuno, se pueden tener caballos y ganado lanar sin recelo que los indios lo roben. ${ }^{55}$

y son justamente tales condiciones las que lo hacían más proclive para permitir la entrada hacia el interior del continente de las potencias extranjeras:

Que el arte debe intervenir para defenderla por medio de la fortificación... Fijados que fuesen en este río y puerto de San José los enemigos, ya estaban en proporción de invadir

\footnotetext{
${ }^{54}$ Vertiz a Gálvez, Montevideo, 22 de febrero de 1783, Audiencia de Buenos Aires, 326.

${ }^{55}$ Villarino, 5:223.
} 
a Buenos Aires, Córdoba, Mendoza, Valdivia y otros muchos pueblos; pues aunados con los indios que habitan estos vastos países, sería dificultosísimo hacerlos retroceder. ${ }^{56}$

La propuesta de Vertiz fue aprobada por la Corona a través de la Real Orden del 1 de agosto de 1783. Por la misma se disponía el abandono de todos los establecimientos patagónicos, "exceptuando el de Río Negro que ha de mantenerse con un comandante militar que se nombre y la corta población que puede hacer a su abrigo, y que en los puertos de San José, San Julián y Deseado, se dejen pilastras, que acrediten la pertenencia a S.M.C. reconociéndose desde Río Negro anualmente cuando se ejecute esta diligencia respecto del Puerto Egmont.",57

Sin embargo, cuando el Marqués de Loreto asumió como Virrey del Río de la Plata, (1784-1789) recibió la orden de revisar dicha decisión. Loreto se mostró proclive a la preservación de los asentamientos. Entre los informes que acompañó la decisión del Marqués de Loreto de mantener estas poblaciones estaba el del Ingeniero Custodio Sá y Faría. ${ }^{58}$ Custodio Sá y Faría pensaba los establecimientos no únicamente como red de defensa costera, sino como puntos en el avance de la frontera colonial de la Patagonia. De manera que además de recomendar la conservación de la población de Río Negro, San José y de repoblar San Julián, propuso el alzamiento de otro "en la punta del este de la Sierra del Volcán, que podría ser en el sitio donde los jesuitas habían dado principio a una reducción de indios pampas, llamada Nuestra Señora del Pilar, que se abandonó." Debe destacarse que en este momento la Sierra del Volcán (actual Sierra de la Ventana) era centro de aprovisionamiento de ganado para los indígenas y punto terminal de sus rutas. ${ }^{60}$ Custodio Sá y Faría estaba teniendo en cuenta así no sólo la necesidad de frenar el avance de otras potencias coloniales sino la posibilidad de ocupar los territorios indígenas en el área comprendida entre Buenos Aires y el Río Colorado incorporados a

\footnotetext{
${ }^{56}$ Ibid., 5:224.

${ }^{57}$ Audiencia de Buenos Aires, 327.

${ }^{58}$ Custodio de Sá y Faría se había desempeñado como cartógrafo de la Corona Portuguesa. Partícipe de las comisiones demarcadoras de los límites entre las colonias españolas y portuguesas en América Meridional correspondientes al Tratado de Madrid (1750) entregó planos de Brasil pertenecientes a la Corona Portuguesa a la expedición de Pedro Cevallos organizada en 1776. A partir de este momento comienza a trabajar a servicio de la Corona Española (Conversación con Max Guedes en el IX Curso de Historia de la Cartografía, Cartografía Iberoamericana, Instituto Cartográfico de Cataluña, Departamento de Geografía de la Universidad Autónoma de Barcelona, Barcelona, febrero de 1998).

${ }^{59}$ Custodio Sá y Faría, Segundo Informe sobre el Puerto de San José, Colección, 5:192.

${ }^{60}$ R. J. Mandrini, "Las fronteras y la sociedad indígena en el ámbito pampeano," Anuario IEHS, no. 12 (1997).
} 
los circuitos de comercialización e intercambio indígena. En este contexto, el traslado de la línea de frontera buscaba obstaculizar las actividades indígenas a partir de la apropiación de aquellos sitios que se consideraban claves para su desarrollo:

A V. E. he oído reflexionar muchas veces cuanto sería importante al real servicio y en utilidad de los moradores de esta capital, que las guardias que guarnecen la frontera para embarazar las incursiones de los indios pampas, se avanzasen a más distancia de la en que se hallan, no sólo para desahogo de las estancias de ganados, como para prevenir a que los indios no llegasen con tanta facilidad a los sitios poblados a robar y matar los pobladores. Este proyecto sería muy conveniente poderle poner en práctica, pues vemos la opresión en que está la frontera ha tantos años, sin poderse dilatar sus moradores fuera del cordón que forman las guardias. ${ }^{61}$

La propuesta de Custodio Sá y Faría elevada al Marques de Loreto demostraba entonces que el mantenimiento de los establecimientos patagónicos, desde su punto de vista adquiría un doble sentido. Por un lado, dificultaba que los barcos ingleses se internaran y lograran penetrar al territorio, que como sostenía Villarino, podría ser facilitada en caso de aliarse con los indígenas del área. Pero, por el otro, los establecimientos se presentaban como la línea terminal de una serie de puntos de avance de la frontera con la población indígena, que tendría su continuidad en los fortines de Buenos Aires y que, por lo tanto, podrían significar el avance de la frontera de Buenos Aires hacia el Oeste. Esta línea Norte-Sur sería complementada con otra que podría levantarse hacia el interior a partir del alzamiento de una fortificación sobre el río Colorado (Choele Choel) propuesta por Villarino. Ella cortaría el camino seguido por muchas de las poblaciones indígenas y, además, agilizaría la comunicación y el comercio entre Buenos Aires, Río Negro, Mendoza y Valdivia.

Podemos inferir entonces que desde la perspectiva de Custodio Sá y Faría, de Villarino y de Francisco de Viedma esta comunicación permitiría una integración de los territorios patagónicos al Virreinato del Río de la Plata. Así, los establecimientos dejaban de tener una significación limitada a contener la penetración inglesa, para cumplir una función de incorporar el área al proyecto territorial hispánico más global contenido en la conformación de la unidad jurídico-administrativa constituida en 1776.

\section{E. La cartografía en el proceso de avance de la frontera patagónica}

\footnotetext{
${ }^{61}$ Sá y Faría, 5:191.
} 
La producción cartográfica aparece como uno de los instrumentos ampliamente utilizados en el proceso de avance de apropiación patagónica sudoriental. Las instrucciones dadas a los expedicionarios y comisarios intendentes de San Julián y Bahía Sin Fondo contemplaban la elaboración de mapas. La representación cartográfica se presentaba así como un instrumento de apropiación territorial, ${ }^{62}$ que más allá de su precisión implicaba que el reconocimiento del pretendido territorio de dominación había sido realizado. De esta manera la producción cartográfica cumplía un fin específico en el ámbito metropolitano. En primer lugar, ella se constituía en una justificación de las reivindicaciones que apoyaban las posturas de la Corona Española en la arena internacional. En segundo lugar, la cartografía se presentaba como un documento que permitía a los diferentes funcionarios acceder a información respecto a los territorios coloniales que el Virrey, los Ministros del Consejo de Indias, o el propio Rey no podían captar en forma directa. En tercer lugar, el mapa era considerado la representación del escenario donde se debían llevar a cabo las diferentes operaciones de política territorial; sobre el mismo se diseñaban diferentes propuestas de reconocimiento y ocupación. Por su parte, los funcionarios encargados de realizar los reconocimientos en el terreno podrían ilustrar sus informes y sus propuestas de política territorial a través de la producción cartográfica.

El mapa que acompaña la documentación que el Marqués de Loreto dirigió al Consejo de Indias con motivo del mantenimiento de los establecimientos patagónicos es una verdadera carta de presentación de la actividad realizada en materia de avance de la frontera colonial y aquella que queda pendiente de efectuar (mapa 1). Como hemos ido afirmando, si bien la erección de las poblaciones patagónicas no tenía otro objetivo que defender la costa oriental sudatlántica de la amenaza inglesa, poco a poco, se fue perfilando también un objetivo complementario de dichos asentamientos. Se trataba de ganar los terrenos hasta entonces incorporados a la economía y a las actividades de los indígenas de la región. El "Mapa geográfico que comprende todos los modernos

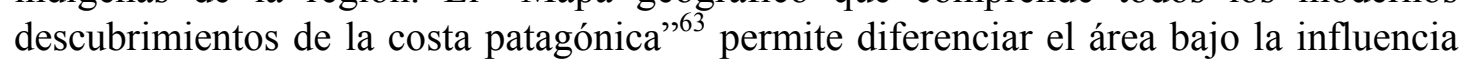
indígena de la otra que se encuentra bajo dominio español, o que por lo menos, ha sido

\footnotetext{
${ }^{62}$ C. Jacob, L'empire des cartes: Approche théorique de la cartographie à travers l'histoire (París: Bibliothèque Albin Michel, 1992); D. Wood, "How Maps Work," Cartographica, no. 29 (1992): 3-4; M. Escolar, "Exploration, Mapping and Development of State Power," International Social Sciences Journal, nos. 141-2 (1996); y M. H. Edney, "Reconsidering Enlightenment Geography and Map Making: Reconnaissance, Mapping, Archive," en Geography and Enlightenment, ed. D. N. Livingstone y W. J. Wither (Chicago: University of Chicago Press, 2000).

${ }^{63}$ Archivo General de Indias, Mapas y Planos, Buenos Aires, 64.
} 
reconocida por diferentes expediciones hispánicas. En la primera el territorio se representa vacío. En el mismo no se diferencian ningún tipo de accidentes geográficos, aún cuando ellos recibieran denominaciones indígenas. Tampoco se ha cartografiado la localización de las diferentes parcialidades indígenas. Todas las características físicas como demográficas del área se licúan bajo la siguiente frase "Terreno habitado por varias Naciones de Indios bárbaros e ignorado de los Españoles." Desde el punto de vista político era entonces más efectivo demostrar la ignorancia en el conocimiento del área, que presentar a estos terrenos habitados por "naciones" cuyas diferencias eran conocidas por la población hispánica como lo muestra el párrafo del texto de Antonio de Viedma citado donde se distingue la jurisdicción territorial de cada cacique. Estas poblaciones otorgaban nombres peculiares a los diferentes "parajes" y, por lo tanto, ejercían un dominio efectivo sobre el mismo. En contraposición, el área bajo la influencia española aparece representada con mayor detalle, los accidentes geográficos, ríos y sierras aparecen con sus topónimos en español.

Esta división entre lo conocido y lo ignorado configura la carta y es justamente esta distinción la que permite hacer la diferenciación entre las áreas que ya han sido reconocidas en el proceso de avance de la frontera colonial y aquellas otras que forman parte de los planes futuros, para los cuales, la manutención de los establecimientos ya organizados desempeñaban un importante papel. Así, por ejemplo el Golfo de San Jorge, del cual reza el mapa "no se acabó de descubrir dicen los Indios que llega hasta la cordillera." El reconocimiento del Golfo de San Jorge pasa a formar parte de los futuros planes de la apropiación territorial de la costa patagónica. 


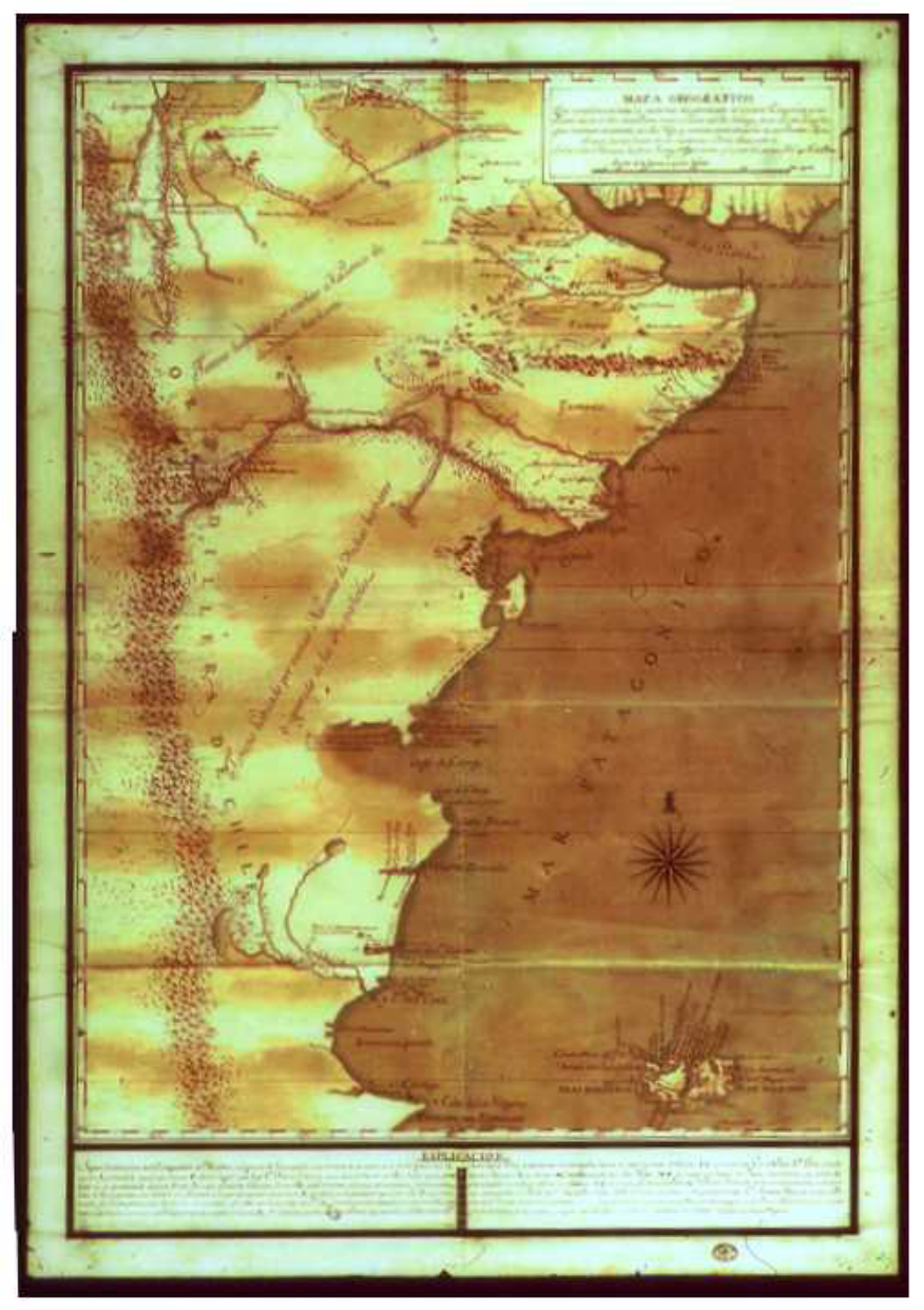

Mapa 1. Mapa geográfico que comprende todos los modernos descubrimientos de la costa patagónica. (Tomado de Archivo General de Indias, Mapas y Planos, Buenos Aires, 64.) 
En el "locus" de la frontera el mapa cumple así la función de dejar constancia acerca de las tareas que quedan pendientes de llevar a cabo en el avance de la frontera. Diferenciar lo conocido de lo ignorado significa distinguir los terrenos que quedan por explorar, identificar la línea actual y proyectada de fortines (señalada con letras del alfabeto) implica organizar las acciones para asegurar la posibilidad de expandir los ámbitos geográficos bajo dominio colonial. Este tipo de acciones asegurarían el dominio efectivo del territorio patagónico comprendido en el Virreinato del Río de la Plata.

\section{F. La frontera colonial patagónica: entre el lugar y la línea}

La frontera colonial patagónica aparece como un lugar con una serie de particularidades. Es continente de un conjunto de instituciones (los establecimientos), de prácticas (exploración, ocupación, tentativas de explotación de pesca y sales), de sujetos (indígenas, colonizadores peninsulares, comisarios superintendentes, exploradores) y de modos de vida (comercio de ganado, explotación de sales, establecimiento de alianzas políticas, entre otros). Ella adquirió presencia material a través de la red de establecimientos erigidos por indicación de la metrópoli y a través del trazado de líneas imaginarias en los mapas del área.

Las actuaciones y representaciones del "otro" determinaron el tipo de acciones realizadas por la Corona Hispánica para definir la frontera patagónica. Desde el levantamiento de los establecimientos, su propuesta de ocupación con población peninsular, hasta la decisión de su mantenimiento o desalojo estuvieron signados por la supuesta amenaza inglesa de ocupar estos territorios y/o por el interés de hacer avanzar la frontera sobre territorios indígenas o interrumpir sus circuitos comerciales.

Las prácticas de diferentes sujetos situados en distintos lugares, se yuxtaponen, confluyen y constituyen el lugar de la frontera. Así es posible distinguir las prácticas metropolitanas de aquellas del Virrey situado en Buenos Aires o de las propias autoridades de los establecimientos. Mientras que las autoridades metropolitanas proponen la construcción de alianzas con los indígenas para contar con aliados frente al avance inglés, las propias prácticas en el lugar de la frontera hacen del vínculo con la población indígena una necesidad. Mientras que el Virrey es partidario del desalojo de los establecimientos, siendo este el principal informante de la metrópoli, las autoridades situadas en las propias poblaciones son partidarias de su mantenimiento. 
Las prácticas materiales se solapan con aquellas vinculadas a la representación cartográfica. Esta representación ofrece una idea particular de la frontera. La línea imaginaria que une a los establecimientos con los fortines de la campaña bonaerense, sólo constatable en la cartografía, aparece como la substanciación material de un momento determinado en el proceso del avance de la frontera con respecto a los terrenos apropiados por los indígenas y como el punto de partida para continuar con la tarea de ocupación territorial. La misma es el referente imaginario de las apropiaciones pasadas y aquellas a ser emprendidas en el futuro. La línea cartográfica refuerza la separación entre el mundo civilizado de aquel "otro no incorporado a la civilización."

En síntesis, las prácticas materiales y las representaciones confluyen en la constitución de la frontera patagónica entendida, a la vez, como una línea (cartográfica) que da cuenta de las acciones de avance, conservación y defensa con relación a la población indígena $\mathrm{u}$ otras potencias coloniales, $\mathrm{y}$ como un lugar donde confluyen distintas prácticas desde aquellas vinculadas a la diferenciación con aquellas otras que tienen que ver más con la negociación, el intercambio y la convivencia. 